Fecha de recepción: agosto 2014 Fecha de aceptación: octubre 2014 Versión final: marzo 2015

\section{El Virus de la Destrucción, o la defensa de lo inútil}

Enrique Rivera Gallardo *

Resumen: ¿Es la ciencia y la cultura un bien de consumo?, ¿hemos transformado lo que alguna vez vez fue sagrado -o símbolo de la dominación mediante la religión-, en un nueva herramienta de control colectivo? ¿ es la tecno ciencia un campo de acción esclava del libre mercado para subvertir a las masas, mas que para generar operaciones de trascendencia social?

Cine, arte, video juegos, la imagen técnica como la llamaría Vilem Flusser, en relación a la dromología de Paul Virilio y a la modernidad liquida de Zygmunt Bauman, evidencian una serie de condiciones tecnopoliticas que determinan el híbrido tecnología militar y sociedad, donde el lenguaje es una especie de virus de la destrucción, donde lo inútil y la suspensión voluntaria de la lógica parecen en este contexto, las únicas zonas autónomas temporales del sentido común.

Palabras clave: Neo-ruralismo - p2p - cultura libre - artes mediales - ubicuidad.

[Resúmenes en inglés y portugués en las páginas 106-107]

${ }^{(*)}$ Investigador, realizador audiovisual, curador y gestor cultural chileno. Actualmente es presidente de la Corporación Chilena de Video y Director de la Bienal de Video y Artes Mediales, encuentro que se desarrolla desde 1993 en Chile.

\title{
Preámbulo
}

A mediados del siglo veinte en Chile comienza un importante quiebre entre artistas y una institución académica del arte que no lograba salir de una tendencia criollista y decimonónica. Este quiebre, influenciado directamente por la primera guerra mundial y su efecto traumático en la producción cultural global, se representó mediante una vanguardia literaria y plástica influenciada e influenciante de los movimientos artísticos europeos y occidentales en general, mediante los puentes que, entre otros, Luis Vargas Rosas el poeta Vicente Huidobro y el pintor Camilo Mori establecen específicamente entre Chile y Francia. El pintor chileno Marco Bontá reflexionaría sobre esta condición de la siguiente manera: "Desde 1900 y más acentuadamente a partir de la guerra de 1914, París vive convulsionado en el plano de las ideas pictóricas. Una revolución se ha planteado entre los llamados 'viejos moldes' y el 'arte moderno"'. 
En 1923, por otro lado hay una bonanza económica que sostiene una serie de estructuras que están en permanente dinamismo. El estado de bienestar demanda gran cantidad de organismos e instituciones para realizar sus proyectos, la ciudad se convierte en el reemplazo natural de la vida campesina, y se contrasta con la vida mediante una profunda brecha social que la separa del resto de la sociedad, aun en el siglo diecinueve.

En lo que respecta al estado del arte en tanto disciplina, hay un esfuerzo permanente por liberar a este del esnobismo y elitismo tradicional de la alta cultura; poetas, pintores y políticos se ocupan de tejer una nueva trama que haga posible una experiencia artística para todos. En los años ‘50 la solidaridad y el folklore emergen gracias a la fuerza y porfía de Violeta Parra, tal vez la primera artista integral e interdisciplinaria chilena, representante de la tendencia autonómica y autóctona de la sabiduría popular de Chile, que se funden con una generación de dirigentes, artistas e intelectuales que inician un movimiento creativo y con una identidad basada en una estética y contenidos pre-colombinos ${ }^{2}$.

Desde mediados de los años '50 Nicanor Parra, pilar fundamental de la relación arte y ciencia en Chile, representa la imaginación contestataria ante el formalismo literario desarrollando un camino propio llamado antipoesía. En los años ‘60 y ‘70 la nueva canción chilena, la fuerza en la divulgación cultura de la editorial Quimantu, la preocupación del Instituto de Tecnologías de Chile por desarrollar productos conscientes de la ergonomía chilena, y las obras de artistas y científicos chilenos como Juan Luis Martínez, Carlos Ortuzar, Juan Carlos Martinoya con Nahum Joel, Juan Downey, entre otros, potencian una configuración madura y que llama la atención de la escena internacional. Artistas y científicos inician un proceso de integración dando paso a un ambiente interdisciplinario que hizo posible incluir nociones estéticas y poéticas en la arquitectura, obras civiles y la ciudad en general, sacando el arte a la calle, y vinculándolo a una experiencia cotidiana. Todo esto se quiebra en el Golpe de Estado de 1973.

El investigador chileno David Maulen en el texto "Una formulación sudamericana del concepto de INTERFASE"', describe este período usando la experiencia de Martinoya como eje referencial: Juan Carlos Martinoya R., ingeniero civil, profesor e investigador universitario, militante de izquierda, físico, investigador en percepción visual, artista kinético; a fines de los años sesenta y principios de los setenta, en Chile, coordinó un grupo interdisciplinario en el que se contaban dos psico fisiólogos (Gui Santibáñez, Susana Bloch), un director de teatro (Pedro Orthus), dos artistas visuales chilenos que habían sido becarios del C.A.V.S. M.I.T. (Virginia Huneeus), y de la New School of Social Research (Carlos Ortúzar), un antropólogo (Arístides Giavelli) y un sociólogo (Luis Strozzi). Eventualmente un biólogo, y otros. Además de la Universidad de Chile, una vez exiliado trabajó en la C.N.R.F.S. de París (en colaboración frecuente con Francisco Varela). Su primera experiencia con el "abstractoscopio cromático" apareció en el número uno de la revista Leonardo en $1968^{4}$.

La vida universitaria está en uno de los puntos más altos de la historia del país, y su interacción con el mundo público se concreta en diversos campos integrando parte de un tejido hoy administrado por empresas privadas. La producción de saber modela las instituciones según los requisitos propios de los distintos dominios temáticos e ideológicos con los cuales se vincula. Es en este escenario donde intelectuales de diversas índoles encuentran puntos comunes y proponen nuevos modelos de desarrollo, y este es el caso 
de Carlos Martinoya y Nahum Joel, quienes experimentaban un profundo compromiso social influenciado por su paso por las juventudes comunistas y sus intereses filosóficopolíticos, donde proponen diversas estrategias incluidas en un programa o/y una actitud política determinada.

\section{"Ya tenemos la técnica, ¿Y ahora qué?"}

Maulen citando Martinoya, 1970.

Lo que Martinoya sugiere con su provocadora pregunta es: una vez alcanzado cierto umbral técnico ¿no es acaso necesario replantear o al menos revisar los modelos y escenarios en donde se utiliza la técnica?

Seguramente influido por su propia experiencia de vida, donde experimenta en carne propia la precariedad de nacer en un contexto social determinado, Martinoya intuye la insuficiencia de una serie de escenarios, es en este contexto en donde dirigió el Laboratorio de Física Nuclear Pura y Aplicada de la Universidad de Chile, y pavimenta el camino para las licenciaturas de matemática y biología. Hasta esa fecha quien quisiera ser físico, matemático o biólogo debía cursar una carrera completa para luego especializarse, su esfuerzo tendía a hacer más expedito ese tránsito y menos sujeto a burocracias, este mismo espíritu lo llevaba a oponerse a la idea de la compartimentación del conocimiento, propone un saber integrador y lucha contra la excesiva especificidad de las disciplinas. Dicha visión parece haberla extraído de su formación marxista. (Maulen, 2012)

El espacio público sirvió como escenario para llevar a cabo esta reconquista de un bien común que nacía de la vinculación arte y ciencia. El diario La Nación publica el 1 de diciembre de 1960 un artículo sobre el Abstractoscopio Cromático, el cual formaría parte de la Feria de Artes Plásticas en el Parque Forestal. En este Nahum Joel declara:

Ciencia y arte están íntimamente ligados; de un lado la estética y la imaginación desempeñan un papel importante en el desarrollo de la ciencia, y por el otro lado, la comprensión de las fenómenos naturales (como el que da base a nuestro abstractoscopio), ayuda a disfrutar mejor las obras de arte.

En el mismo encuentro donde Violeta Parra exhibía sus arpilleras, los colores proyectados por el Abstractoscopio complementaban un encuentro influenciado por la apertura y solidaridad, mientras en los espacios clásicos del arte y la ciencia era desconocido, situándose en un limbo descontextualizado. Germán Gassman, abogado y organizador de la Feria de Artes Plásticas junto a Lorenzo Berg -uno de los pioneros del land art en el mundo-, fue un precursor de la transdisciplinariedad de tendencias, técnicas y públicos, realizando en 1959 el primer encuentro, y denominando la iniciativa en el segunda versión como Museo de Arte Moderno, iniciativa que sirvió como escenario para presentar el Abstractoscipio Cromatico a más de los 300 mil asistentes al encuentro. En el libro Nosotros los artesanos, y las ferias de artesanía del siglo XX, de Alicia Cáceres y Juan Reyez, encontramos el siguiente texto: 
Asimismo, con naturalidad, se fueron dando las cosas para llegar en noviembre de 1960, a la fundación del Museo de Arte Moderno (MAM); entidad sin territorio físico, y que, como dijera don Germán, tenía su sede "allí....bajo los árboles del Parque Forestal"s.

El escenario fue ideal para presentar esta iniciativa, que tenia como uno de sus principales creadores a Martinoya, generando coherencia con una idea de sobreponer los bienes comunes por sobre el ego centralizador del arte y de las ciencias modernas, y el asbtractoscopio es un ejemplo de ello. En 1958, Nahum Joel funda el Departamento de Cristalografía de la Universidad de Chile, e invita a Martinoya a trabajar en diversos experimentos físicos mediante la utilización de cristales que detonaron la exploración perceptual de estos medios, los que dieron como resultado el Abstractoscopio Cromático, el cual tenía como motivación noble y, al mismo tiempo, provocadora popularizar la creación artística. Con dicho instrumento cualquier persona podría producir sus propias obras de arte, esta idea se condice muy bien con la actitud social que caracterizaba a Martinoya, además de proponer una herramienta científica para que la gente común experimentara un puente entre disciplinas, creando una acción pionera y transformativa -tal vez sin proponérselodel quehacer y la producción artística. Según lo anterior podemos ver que la revolución del abstratoscopio no es necesariamente su novedad técnica sino más bien el contexto y la pregunta que motiva su formulación, así como todas las interrogantes que hasta hoy sugieren su re- descubrimiento. Lo trascendente del Abstractoscopio es precisamente la inducción de un cruce disciplinar, inducción que es respuesta a una problematización política y social más amplia, donde el concepto de "interface" de Gui Bonsiepe aplicado en Chile a fines de los '60 es fundamental:

La Hoschule für Gestaltung de la ciudad de Ulm, fue un claro experimento de intentar otra Bauhaus Dessau después de la segunda guerra mundial, entre los años 1955 y 1968. Gui Bonsiepe viene de esa escuela, que más que ser solo un instituto politécnico, era un intento radical de reconstrucción del sujeto, la eliminación de las disciplinas parceladas y descontextualizadas por un planteamiento integral a través de las disciplinas proyectuales.

En su ensayo, Maulen realiza una revisión del contexto filosófico-político que se desarrolla en Chile entre los años 1925-1973, donde el diseñador alemán Gui Bonsiepe propone una filosofía solidaria que se conecta a los planteamientos horizontalistas de Martinoya. En ella expresa como la Hochschule für Gestaltung de Ulm tuvo una influencia simbólica en Chile mediante tres pilares fundamentales: La teoría crítica de la escuela de Frankfurt, que aportaría la visión sociológica en relación a una crítica económica, a propósito de las técnicas y tecnologías desarrolladas en este contexto, y los sistemas de distribución de los productos. Menciona además la influencia del Circulo de Viena desde un carácter neopositivista, donde Wittgnestein y su "Tractatus lógico filosófico". Finalmente, y citando nuevamente a Maulen, está la influencia de Jean Baudrillard y su "Crítica a la Economía política; del signo": "no existe límite para las "necesidades" del hombre en tanto ser social... la absorción cuantitativa de alimentos está limitada... pero el sistema de la alimentación es infinito". 
En este contexto, la realidad socio política de Chile, que se enfrentaba al desafío de constituir un sistema propio, desde la visión de una tercera vía, diferente al capitalismo y al comunismo, basado en un alto empoderamiento de las bases mediante el sindicalismo, la nacionalización de la producción del cobre y otros recursos naturales, fue interrumpida traumáticamente, provocando la aplicación de uno de los modelos capitalistas más salvajes que han sido implementado a nivel global, afectando no solo los medios de producción, si no en la constitución de una identidad basada en nuestra propio contexto.

Hoy nos enfrentamos a la constitución de nuevos escenarios sociales y económicos, donde la invisibilización de los medios y su ubicuidad, u omnipresencia, evoca la distopía de Un Mundo Feliz de Aldous Huxley. Presenciamos como lo que antes era evidente, hoy se miniaturiza y desvanece lentamente frente a nuestros ojos, como ondas electromagnéticas que viajan sin que lo percibamos, afectando directamente nuestras vidas.

\section{Heterarquía y descentralización}

"Pronto las relaciones humanas no podrán existir fuera de los espacios de comercio". (Nicolás Bourriaud)

2014. En Chile luego del golpe militar los avances que se venían desarrollando en los ‘ 60 y principios de los '70 fueron aplastados por el miedo que inundaba el mundo producido por la mal llamada "amenaza roja", influenciada en el inconsciente colectivo global por las herramientas de control masivo propuestos por Edward Bernays en su estrategia de control colectivo llamado Relaciones Públicas, que fusionaba técnicas del psicoanálisis y la propaganda nazi para la manipulación mediante la percepción, aplicado por empresas multinacionales de Estados Unidos. En un país donde la investigación teórica y tecnológica crecía equitativamente, hoy parece que los avances tecnológicos se han adelantado al sistema de pensamiento filosófico, ético y cultural, generando verdaderos abismos entre las posibilidades y responsabilidades de manejar herramientas que determinan el vivir colectivo. La tecnología digital se instala en las comunidades como una especie de monolito extraterrestre que contiene las herramientas que nos llevarán a trascender y construir una sociedad más abierta y equitativa, donde los conocimientos fluirán libremente. O por lo menos esa es la promesa democrática.

Resulta que en la practica, muchas veces esta tecnología produce mas bien una brecha no solo entre quienes tienen o no acceso a estas, sino que también entre quienes las utilizan, llegando a cometer actos de irresponsabilidad desastrosos. Estas personas trabajan no solo en sectores privados -que en una sociedad neoliberal manejan y lucran a partir de los bienes comunes-, si no que más grave aun, también en el Estado, provocando a partir de un uso limitado de las tecnologías, estancamientos y errores no forzados que afectan a millones de personas.

El escenario global se mueve con rapidez despiadada y, quienes se quedan atrás, sufren consecuencias que no solo los afectan a ellos, si no a una comunidad que ya no puede considerarse separada de las socio-tecnologías. El periodo de transición análogo-digital no esta en cuestión, es nuestra capacidad por no solo adoptar, si no también desarrollar, 
los sistemas que determinarán el inicio de una era condicionada por el tiempo real y la ubicuidad.

La necesidad de espacios de reflexión critica a esta condición, que reúna a pensadores y realizadores que trabajan en torno a estas practicas para reforzar el pensamiento abierto sobre una filosofía de la cultura digital, y la relación arte, ciencia y tecnología en el contexto latinoamericano, no es solo una necesidad lógica, si no que urgente. Esto con el objetivo de potenciar una reflexión que incluya el aporte de filósofos y sociólogos que provoquen a partir de una reflexión ampliada, la búsqueda de una política aplicada a estos cambios de paradigma que son transversales no solo en el contexto teórico, si no también político. Esto ya fue desarrollado una vez en Chile. Durante el gobierno de Salvador Allende, Stafford Beer aplicó sus nociones cibernéticas sobre el Modelo de Sistema Viable en el proyecto Cybersyn, que interconectaría a las diversas provincias a tiempo real. Este proyecto, hoy conocido como una especie de proto internet socialista, es reflexionado por el ingeniero computacional José Flores, quien en una conversación en una red social anuncia a propósito de Cybersyn ${ }^{6}$ y su posibilidad de ser aplicado hoy:

Hacerlo realidad significa poner al pueblo, con la diversidad de pareceres, a la cabeza de la gobernabilidad. Siguiendo la naturaleza recursiva del modelo, la retroalimentación también debe ocurrir a nivel del trabajador y su grupo familiar. Ahí creo está lo más complejo, el sentido de pertenencia a un organismo diverso en que se debe tener claro la dirección, sentido y magnitud del avance hacia nuestro destino. Para ello debemos ser capaces de dar continuidad de largo plazo a una idea pretérita que nos identifique, suponer luego que los problemas mundanos de la desigualdad y la injusticia han sido resueltos, para recién ahí estar listos para florecer y mostrar nuestro aporte al mundo. Que España no nos haya derrotado durante la conquista es a mi juicio el punto de partida que nos identifica., solo tenemos que redescubrirnos ${ }^{7}$.

Este eterno redescubrimiento, es un proceso que define nuestro contexto latinoamericano, donde la invención de tecnologías sociales aplicadas a nuestro contexto, determinan nuestra real autonomía de los sistemas políticos y económicos que surgen de este escenario post colonialista. Post producción, hetarquía y descentralización son entonces claves fundamentales para la constitución de vías alternativas de gestión de nuestras propias relaciones, configuradas a partir de realidades geográficas y psico-geográficas que trascienden la explotación de recursos naturales, y se instalan en un sector terciario, descrito por Nicolas Bourriaud en su libro Postproducción como: “...un conjunto de actividades ligadas al mundo de los servicios y del reciclaje... opuesto al sector industrial o agrícola de producción de materias en bruto(...)"

La unión de las comunidades de las artes mediales, el hacktivismo y la permacultura, configuran un espacio disruptivo y con la intensidad necesaria para reconectarnos y reconfigurar nuestros propios sistemas. 


\section{Trascender los Medios}

"El medio es el mensaje". (Marshall McLuhan)

"Que importan los medios! lo importante son los contenidos". (Woody Vasulka)

Gracias a internet, nunca en la historia de la humanidad tuvimos un acceso tan directo y fluido a los contenidos producidos por otros como ahora. Nunca tuvimos la posibilidad de instalar de una forma tan masiva nuestras ideas, obras y reflexiones. Se han iniciado revoluciones, caído dictaduras eternas y posicionado políticos vacíos que no tienen más que carisma y mucha ambición. El poder de las imágenes nuevamente ha trascendido el domino del arte, y se ha configurado una nueva religión asociada a las relaciones públicas y los medios. Las tecnologías de la comunicación agregaron un vértigo caótico al sistema político de la democracia, las guerras empezaron a ser transmitidas a tiempo real (tormenta del desierto), google se convirtió en una de los principales oráculos de la post modernidad, y wikileaks remeció la actitud naíf con la que nos relacionábamos con la información manejada por los Estados.

Los contenidos producidos por las multitudes trascienden el espacio local afectando planetariamente a una sociedad bombardeada mediaticamente a través de un sistema interconectado que provoca abismos entre quienes manejan y no la información, acción advertida primitivamente por el movimiento Ludita ${ }^{9}$ anti revolución industrial en la Inglaterra de fines del siglo 19, y visionada por diversos grupos de artistas como el movimiento Futurista y el Fluxus ${ }^{10}$, que antecedían el protagonismo de los medios de transmisión de sonidos e imágenes a tiempo real, posicionando sistemas de dominación y creando un espacio de entropía y resistencia frente a la forma capitalista de manipulación mediática. Tampoco nunca la brecha de conocimientos había sido tan grande entre quienes tienen acceso a esa masiva cantidad de información, y los que no tienen los recursos, tanto económicos como intelectuales, provocando cambios de paradigmas y problemas estructurales frente a una sociedad que parece no adaptarse éticamente aun a los inicios de esta tercera gran revolución de la sociedad, determinada por el control de la electricidad, la computación digital, y la autonomía de las bases, que configura una forma de inteligencia y pensamiento abstracto colectivo diferente al instalado por la revolución industrial, donde las formas jerárquicas y autoritarias, no tienen cabida en una sociedad heterarquica y distribuida. La horizontalidad, autoformación y autogestión, se han convertido en paradigmas de la investigación y producción actual, donde más importante que las herramientas tecnológicas, la actitud proactiva, y la capacidad de trabajo multidisciplinario integran una fuerza transformadora de esta modernidad liquida, como la denomina el sociólogo Zygmunt Bauman ${ }^{11}$, frente a un sujeto determinado por los cambios y la plasticidad de una realidad en constante cambio, donde la inteligencia humana convive con la artificial. Es entonces en este contexto actual, donde conceptos como democracia electrónica, cultura digital y humanidades digitales, vienen a configurar un espacio donde los denominados nuevos medios -que evocan una clave tecno-científica-, dan paso a un contexto donde el contacto humano vuelve a predominar frente a un posible volcamiento tecnofilico irreversible, que esta generando patologías sociales colectivas disociadas de una ética de interacción armónica entre humanos y máquinas. 
Chile es un país que tiene complejo de isla, separado por los andes, el desierto, el océano y el continente antártico. Su problema con las semillas transgénicas es muy similar al de la implementación de sistemas operativos en contextos educacionales y de labor Estatal; una vez que entran, es muy difícil erradicarlos. Cuando le enseñas a una persona a utilizar ciertos sistemas operativos computacionales, generas un marco de dependencia y compatibilidad. Y en general lo que ha pasado en Chile, es que grandes empresas multinacionales ofrecen sus sistemas operativos gratuitamente en una primera instancia, provocan un sistema de dependencia, y luego venden estos sistemas operativos a los gobiernos de turno, que no solo compran una forma de conversar, interactuar y crear con y desde el computador, si no también la base estructural de esta tercera revolución industrial. El sistema es similar al del traficante de drogas, pero esta vez, es una droga que se mete en cada uno de los intersticios de la sociedad, creando entes esclavizados a un tipo de conducta que tiene como resultado un sistema de dependencia y control absoluto de la información producida y compartida atentando contra nuestra privacidad y libertad de expresión. La migración a sistemas operativos libres es urgente.

El caso de Microsoft y Chile es concreto. Mientras en Brasil se levantó una industria de producción de software desarrollado por y para la comunidad -creando una cultura digital que incluía en su estrategia colegios, universidades y empresas locales-, en Chile recibimos con los brazos abiertos la oferta de la multinacional de Bill Gates destrozando una excelente oportunidad (pero no irrepetible), para hacernos cargo no solo de nuestros propios sistemas operativos - que determinan la viabilidad del sistema, como fue visionado en el proyecto Cybersyn desarrollado por Stafford Beer durante el gobierno de Allende $^{12}$, si no que también de dar un paso para dejar de depender de la extracción de nuestros recursos naturales, como la mega minería, industria que a pesar de entregar a Chile una de sus principales fuentes de ingreso, no es eterna, impacta al medio ambiente, y debido a su inminente finalización, nos determina como sociedad a elegir otras vías de sostener estructuralmente nuestra economía.

La construcción de una Cultura Digital basada en nuestra propia ergonomía y geografía psico-social, se basa principalmente en una estrategia de compatibilidades; la metáfora del sistema operativo que es compatible con ciertos software dependiendo de su nivel de actualización, es correcta para entender en este caso, como actualizar nuestras formas y metodologías de integrar un proceso global de aplicación de las nuevas tecnologías de la información y la comunicación en el tejido social. Ya tenemos la tecnología, sabemos que cambia cada 18 meses como es enunciado en la Ley de Moore ${ }^{13}$, y necesitamos adaptarnos constantemente.

La memorización en los procesos educativos quedó obsoleta, las empresas se modernizan y necesitan trabajadores con capacidades tecnológicas en constante cambio, que tengan como base el pensamiento abstracto, la capacidad de discernir frente a una saturación de contenidos que produce una especie de ruido blanco informático. El Estado en este caso necesita volcarse urgentemente a crear sistemas de compatibilidad entre su metaestructura y una sociedad cada vez más participativa, que necesita de los puertos necesarios para conectarse e integrar un espacio común. No es difícil constatar que la demanda por una asamblea constituyente se basa también en un efecto producido por la alta participación en las redes sociales, nos hemos acostumbrado a dar nuestra opinión masivamente, y 
queremos no solo expresarla, si no que tenga un alto nivel de incidencia en las decisiones tomadas por nuestros sistemas de representación política, y esta condición debe ser parte de una futura nueva carta magna.

Así como el artista pionero Juan Downey ${ }^{14}$ anunció mediante su obra que los muros del museo ya no contenían la producción artística de vanguardia, los muros del Congreso Nacional ya no tienen la capacidad de sostener una democracia que esta muy alejada del ágora griega y es incompatible con la realidad social actual. El ágora actual esta distribuida, es a tiempo real, ubicua y mucho más compleja. Sin embargo, este neo salvajismo es aprovechado por los herederos post modernos de Bernays, quienes usan por ejemplo facebook como una herramienta no solo de comercio, donde cada usuario se convierte en la mercancía, si no que tambien de control social y político. Es en ese sentido donde las preguntas planteadas por Noicolas Mavrakis son atingentes: ¿qué es exactamente Facebook? ¿Una versión digital de los salones sociales decimonónicos donde se prueban las aptitudes para la verdadera interacción contemporánea? ¿Un club promiscuo de intercambio de fantasías y exhibiciones a la espera de experiencias vitales? ${ }^{15}$ Este artículo fue realizado a propósito de un experimento en el que participaron 689.000 usuarios de facebook, quienes fueron analizados mediante sus conductas en esta red social.

El poder de una empresa como Fcebook es incalculable, y su valor es solo posible de analizar desde el punto de vista psicosocial. La construcción de una sociedad que logre establecer sus propias redes de comunicación, donde los datos de sus usuarios no dependan de una empresa privada, si no que de cada uno de sus integrantes para evitar su transacción en el mercado de los datos.

Atenuar esta complejidad pasa por un proceso que incluye todos los campos de la formación de una generación que aun tiene la posibilidad de crecer en un ambiente digital ético y sustentable. Este proceso abarca desde la formación preescolar hasta la post universitaria, es a largo plazo, y basada en las nuevas tecnología de la conversación, que nos dirijan a la humanización de una sociedad que viaja directamente a un precipicio tecnofilico.

\section{La Variable Oculta, a propósito de lo inútil}

Tiendo a considerar que lo inútil, condición indefensa frente al exitismo del progreso, se invisibiliza frente a una sociedad sobre estimulada. Nuccio Ordine en su libro La Utilidad de lo Inútil reflexiona sobre la pregunta ¿Es útil lo inútil? y declara:

El oxímoron evocado por el título La utilidad de lo inútil merece una aclaración. La paradójica utilidad a la que me refiero no es la misma en cuyo nombre se consideran inútiles los saberes humanísticos y, más en general, todos los saberes que no producen beneficios. En una acepción muy distinta y mucho más amplia, he querido poner en el centro de mis reflexiones la idea de utilidad de aquellos saberes cuyo valor esencial es del todo ajeno a cualquier finalidad utilitarista. [...] Si dejamos morir lo gratuito, si renunciamos a la fuerza generadora de lo inútil, si escuchamos únicamente el mortífero canto de sirenas que nos impele a perseguir el 
beneficio, sólo seremos capaces de producir una colectividad enferma y sin memoria que, extraviada, acabará por perder el sentido de sí misma y de la vida. Y en ese momento, cuando la desertificación del espíritu nos haya ya agotado, será en verdad difícil imaginar que el ignorante homo sapiens pueda desempeñar todavía un papel en la tarea de hacer más humana la humanidad". (2013, p. 9)

La subjetividad en torno a lo visible e invisible contiene tantas capas complejas como relatos internos y religiosos en cada civilización. Un nuevo tipo de religión, sin un dios determinado, ni estructura clerical definida, pero con una carga icónica que se nutre de los avances multimediales de la intersección literatura, cine y computación, es la agrupada en el universo de las animaciones japonesas. La prolijidad, elegancia y complejidad de sus guiones y estética, han configurado un extenso imaginario que inspira y determina no solo a las generaciones jóvenes de Japón, si no que a un campo transversal etario global. En este imaginario residen una serie de referentes sobre lo oculto y misterioso, lo que habita invisible ante la mirada convencional de los estatutos occidentales. En la descripción de wikipedia ${ }^{16}$ de Tenshi no Tamago (El Huevo del Angel, 1985, Tokuma Shoten, Yoshitaka Amano y Mamoru Oshii), encontramos el siguiente texto:

El Huevo del Ángel (天使のたまご Tenshi no Tamago) La OVA sigue la vida diaria de una niña, cuyo nombre nunca se revela, que guarda celosamente un huevo de contenido desconocido, en un mundo surrealista, post apocalíptico quizás, sumido en la oscuridad y donde aparentemente no habita ninguna persona. Ella ocupa su tiempo recolectando botellas por la ciudad y llenándolas de agua. Se encuentra luego con un hombre que llega montado en una caravana de máquinas y con un arma en forma de cruz en su espalda. El hombre comienza a seguirla, y en un momento después ella se da cuenta que ha extraviado el huevo que guardaba, el hombre aparece entonces y se lo devuelve. Él le pregunta qué hay dentro del mismo. Ella no responde a la pregunta y entonces él le dice que debería romperlo para descubrirlo. Ella pide entonces que no la siga y después que prometa no hacerle nada al huevo.

Cargada de extraños simbolismos, una escena de la película retrata un ejército de fantasmas que intentan cazar la sombra de un monstruo marino, mientras los dos personajes observan esta situación imposible, ya que la ciudad esta deshabitada, siendo la única vida latente, el huevo, que esconde el misterio de su contenido, el hombre, que representa la sobrevivencia post industrial, y la niña de mirada bucólica, que en una ambigüedad evidente, esconde el huevo bajo su vestido frente a su vientre, insinuando de alguna forma un embarazo adolescente, y el alto simbolismo referente a la fertilidad detrás del huevo.

Este huevo representa un velo simbólico entre lo que se presenta social y políticamente invisible en una sociedad inmadura y neo salvaje. Por otro lado, representa también el deseo científico y cultural por lograr la invisibilidad mediante fórmulas basadas en la nanotecnología y los metamateriales ${ }^{17}$. La condición alquímica de transformación de la materia, 
la transmutación de los elementos, sale del espacio injusto de lo ilusorio y se instala en un campo científico aún en desarrollo, donde la investigación artística se debe posicionar en un espacio diferente al de las comunicaciones corporativas en las que en general se considera en el contexto latinoamericano, para, desde su propia condición, crear no soluciones, pero sí incertidumbres a propósito de realidades aparentes desconocidas.

El huevo representa también internet, como un espacio universal que lo contiene todo. Umberto Eco (2013) en ese sentido realiza una ácida descripción de la red:

Internet es como la vida, donde te encuentras personas inteligentísimas y cretinas. En Internet está todo el saber, pero también todo su contrario, y esta es la tragedia. Y además si fuese todo el saber, ya sería un exceso de información (...) Si yo comienzo a estudiar en la escuela necesito un libro así [hace un apócope con las manos], no uno enorme, que no entenderé, a nadie se le ocurre darle la [Enciclopedia] Británica a un niño.

La información y el conocimiento también son tóxicos en exceso.

\section{Notas}

1. Fuente: http://www.memoriachilena.cl/602/w3-printer-3445.html

2. Fuente: http://www.violetaparra.cl/sitio/obra-visual

3. Fuente: http://www.cybersyn.cl/imagenes/documentos/textos/formulacion\%20sudame ricana\%20interfase $\% 20$ chile $\% 201925 \% 201973$.pdf

4. Fuente: http://www.cybersyn.cl/castellano/documentacion/index.html

5. Fuente: http://es.scribd.com/doc/34925729/1/LAS-FERIAS-DEL-PARQUE-FORESTAL -Y-EL-MUSEO-DE-ARTE-MODERNO

6. Fuente: www.cybersyn.cl

7. Fuente: https://www.facebook.com/enrique.rivera.104418/posts/10152193687473587? comment_id=10152196356343587\&offset $=0 \&$ total_comments $=14 \&$ notif_t $=$ share_ comment

8. Nicolas Bourriaud, Post producción. La cultura como escenario: modos en que el arte reprograma el mundo contemporáneo.

9. Fuente: http://es.wikipedia.org/wiki/Ludismo

10. Fuente: http://es.wikipedia.org/wiki/Fluxus

11. Fuente: http://es.wikipedia.org/wiki/Zygmunt_Bauman

12. Fuente: www.cybersyn.cl

13. http://es.wikipedia.org/wiki/Ley_de_Moore

14. "Con energía más allá de estos muros" (With Energy Beyond These Walls) es una scultura que convertía energías invisibles al ojo humano en otras manifestaciones físicas por medio de dos cajas separadas en el espacio que se conectaban a través de ondas de radio y mantenían una conversación entre ellas.

15. Fuente: http://www.revistaenie.clarin.com/ideas/tecnologia-comunicacion/curiosidad -oculta-Facebook_0_1169283097.html 
16. Fuente: http://es.wikipedia.org/wiki/El_huevo_del_\%C3\%Alngel

17. Fuente: http://www.youtube.com/watch?v=faQqRbfZSnE

\section{Bibliografia}

Bourriaud, N. (2004). Postproducción, Buenos Aires: Adriana Hidalgo.

Maulen, D. Una formulación sudamericana del concepto de INTERFASE http://www. escaner.cl

Ordine, N. (2013). La utilidad de lo inútil, Barcelona: Acantilado.

\section{Recursos electrónicos:}

Entrevista a Umberto Eco en El País del 23 de mayo de 2013 realizada por María Antonia Sanchez Vallejo, hallable en: http://cultura.elpais.com/cultura/2013/05/23/actualidad /1369333134_264650.html

http://www.memoriachilena.cl/602/w3-printer-3445.html

http://www.violetaparra.cl/sitio/obra-visual

http://www.cybersyn.cl/imagenes/documentos/textos/formulacion\%20sudamericana\%20 interfase $\% 20$ chile $\% 201925 \% 201973 . p d f$

http://www.cybersyn.cl/castellano/documentacion/index.html

http://es.scribd.com/doc/34925729/1/LAS-FERIAS-DEL-PARQUE-FORESTAL-Y-ELMUSEO-DE-ARTE-MODERNO

https://www.facebook.com/enrique.rivera.104418/posts/10152193687473587comment_id $=10152196356343587 \&$ offset $=0 \&$ total_comments $=14 \&$ notif_t $\mathrm{t}=$ share_comment

http://www.fundaciontelefonica.cl/arte/downey/archivos/parte_1.pdf

http://www.revistaenie.clarin.com/ideas/tecnologia-comunicacion/curiosidad-ocultaFacebook_0_1169283097.html

http://es.wikipedia.org/wiki/El_huevo_del_\%C3\%A1ngel

Summary: Is science and culture a commodity?, Have we transformed what once was sacred -or a symbol of the domination by the religion-, in a new tool for collective control? Is techno-science a field slave of free market to subvert the masses, rather than to generate social significant operations? Film, art, video games, the technical image as it would be called by Vilem Flusser, in relation to Paul Virilio dromology and liquid modernity of Zygmunt Bauman, show a series of techno-political conditions that determine the hybrid military technology and society, where language is a kind of destructive virus, where the useless and the voluntary suspension of logic seem in this context, the only temporary autonomous zones of common sense.

Keywords: neo-ruralism - P2P - free culture - media art - ubiquity. 
Resumo: A ciência e a cultura são bens de consumo? Transformamos aquilo que foi sagrado alguma vez -ou símbolo da dominação mediante a religião- em uma nova ferramenta de controle coletivo? É a tecno ciência um campo de ação escrava do livre mercado para alterar às massas, mas que para gerar operações de transcendência social?

Cinema, arte, jogos de vídeo, a imagem técnica como a chamaria Vilem Flusser, em relação à dromologia de Paul Virilio e a modernidade líquida de Zygmunt Bauman, evidenciam uma série de condições tecno-políticas que determinam o híbrido tecnologia militar e sociedade, onde a linguagem é como um vírus da destruição, e onde o inútil e a suspensão voluntária da lógica parecem neste contexto as únicas zonas autônomas temporais do senso comum.

Palavras chave: neo-ruralismo - p2p - cultura livre - artes mediais - ubiqüidade. 